\title{
Steering test of mid-size bus with flexible-body dynamics model
}

\author{
Jia-Shiun Chen ${ }^{\mathrm{a}}$ and Hsiu-Ying Hwang \\ Department of Vehicle Engineering, National Taipei University of Technology, Taiwan
}

\begin{abstract}
The object of this paper is to analyze the vehicle structural vibration responses during the step steering simulation test. With computer simulations, confirming the influence from the difference between configurations of components on mid-size electrical bus and tradition one could be possible. The difference of the vibration responses between flexible multi-body model and rigid one would be discussed. Since the wheel base of mid-size bus is longer than passenger car, the deformation of vehicle body more obviously influences the output of vibration response. The operating condition in practical driving can be expressed by flexible model, and the performance prediction of vehicle can be closer to the real vehicle behavior. The difference between the flexible body simulation and rigid body simulation is $1.17 \%$, and the flexible body model is more practical.
\end{abstract}

\section{Introduction}

The design requirements of vehicle handling and comfort are considerably important in the field of vehicle design. The major reason is the safety of driver and passengers, and followed by the driving quality of the vehicle. In order to reduce development time and cost, the prediction of the dynamic characteristics of the designed vehicle is required, so vehicle mathematical model which supports the scientific theory to evaluate the traffic safety and quality of vehicles should be established. With the advance of modern computer, computer-aided engineering (CAE) is applied to the vehicle mathematical model.

In 2014, the worldwide sale of global electric and hybrid buses is accounted for $5.6 \%$ of total buses sales, and it is expected to reach $16.9 \%$ in $2020 \mathrm{AD}$. In electric bus, the primary power source is replaced by an electric motor, and the motorizing of powertrain system makes body structure changes along with the increased load on the vehicle battery. The battery weight would change the weight distribution of the vehicle, and cause the impact on handling and comfort during traveling. With CAE's technology, the vehicle dynamic simulation with the overall bus structure could more precisely predict the vehicle behavior during the different maneuver, and improve its handling and comfort.

This research investigated the electric bus stability with different steering inputs, and predicted the dynamic characteristics of the electric bus. The rigid body dynamic simulation model vehicle was established, and then the bus structure was replaced with the flexible body from structure analysis. Both simulation models would be analyzed. This study could present that the application of flexible

\footnotetext{
${ }^{a}$ Corresponding author : chenjs@mail.ntut.edu.tw
} 
multi-body dynamics simulation based on actual body deformation could affect the behavior of vehicle handling simulation, and it could provide more precisely prediction.

\section{Bus model}

The bus CAD model was established with Hyperworks simulation software [1-3]. The model file was read into MotionView along with the sets of suspension systems, tires, steering group and connected components to complete the rigid motion model of electric bus body model, as shown in Figure 1. Later, the rigid bodies in the model were substituted by the flexible body of vehicle structure to build the flexible body dynamic model. Detailed modelling process was shown in Figure 2.

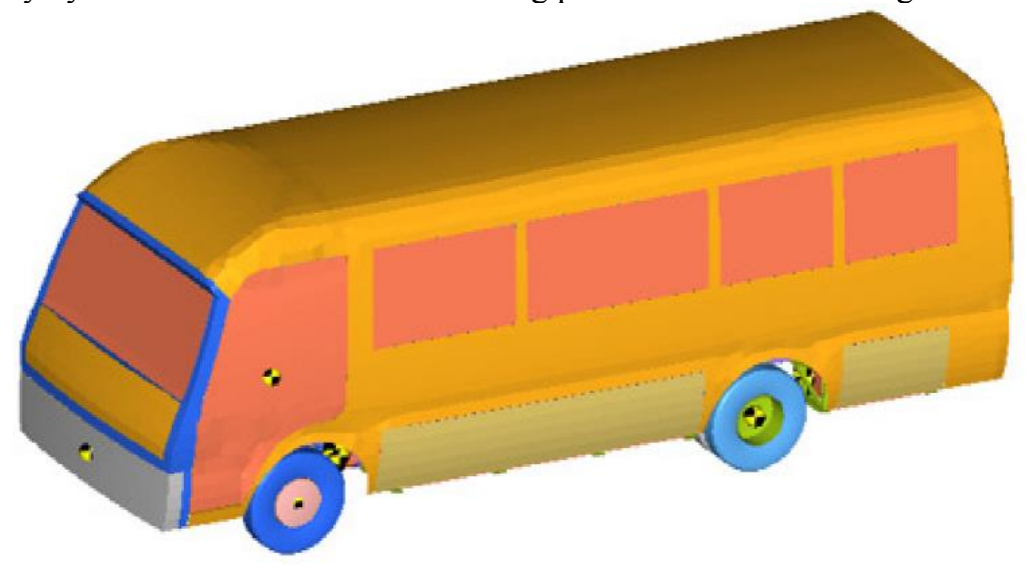

Figure 1. Vehicle model diagram.

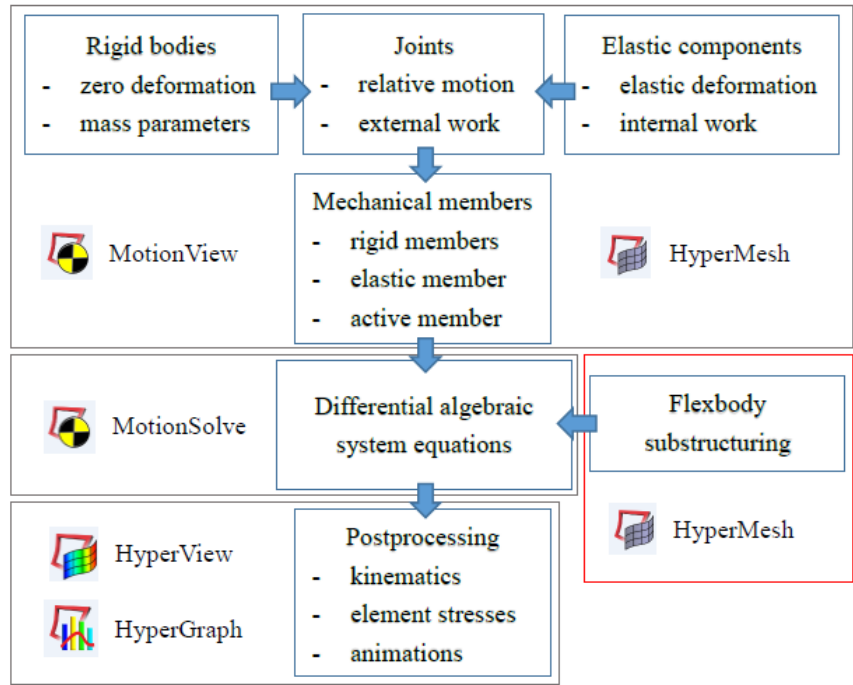

Figure 2. Flowchart of flexible multibody dynamic analysis.

The vehicle model was divided into two major parts: the body structure and chassis structure. The body structure comprised bus body, battery, seat, beams. The chassis structure comprised steering systems, suspension systems, tires, transmission. The body structure was fixed on the top of the chassis structure. The flexible body would replace the rigid body, and it was marked within the red frame. The vehicle structure diagram was shown in Figure 3. 


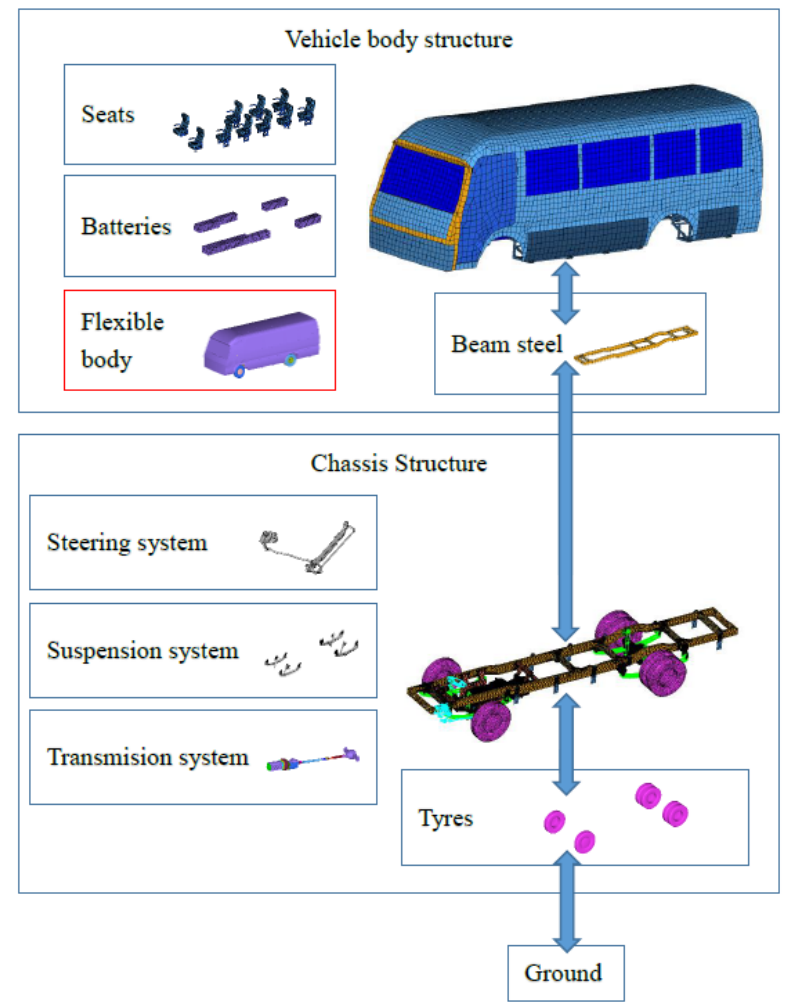

Figure 3. Vehicle structure diagram.

\subsection{Vehicle flexible body structure}

In this study, flexible body structures would replace the rigid body in vehicle dynamic model. The flexible bus body and flexible beams were shown in Figure 4 and Figure 5, respectively. The major selected modes of flexible body were torsional modes, and longitudinal and lateral bending modes. The first three mode shapes were shown in Figure 6. Since large vibration transmitted to the vehicle body is generally below $50 \mathrm{~Hz}$ [4]. The selected modal frequencies were up to $70 \mathrm{~Hz}$, as shown in Table 1.

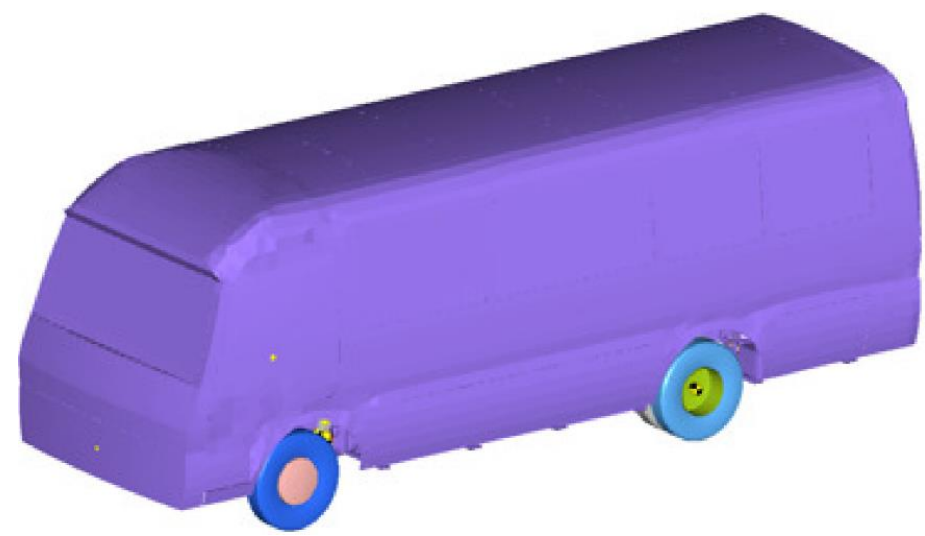

Figure 4. Bus flexible body. 


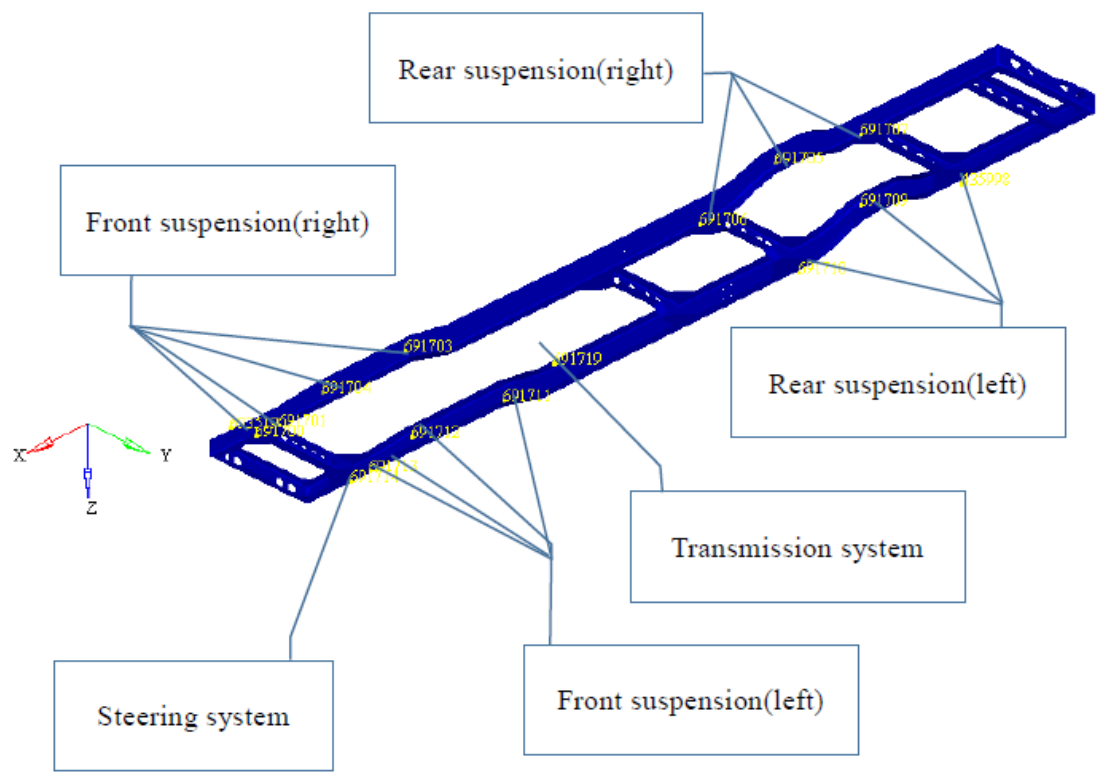

Figure 5. Beam flexible body and binding locations.

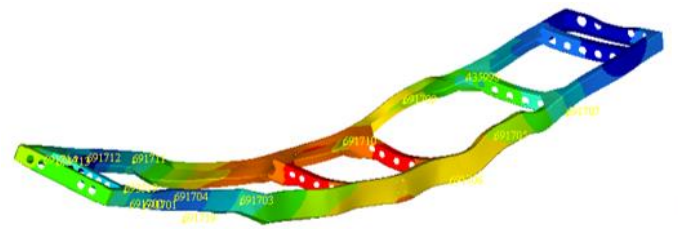

First bend mode $(23.84 \mathrm{~Hz})$

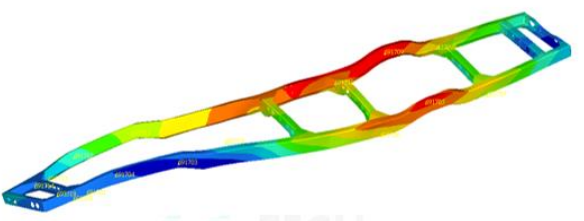

First torsion mode $(27.84 \mathrm{~Hz})$

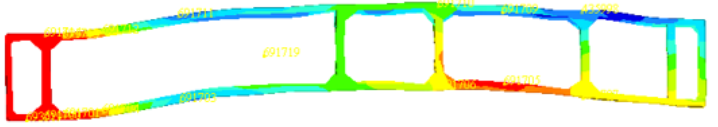

Second Bending mode $(35.86 \mathrm{~Hz})$

Figure 6. First three mode shapes of beam.

\subsection{Steering system}

The vehicle steering system included a steering gearbox to turn the wheel spindles. All parts were considered as a rigid body. The system was shown in Figure 7.

\subsection{Suspension system}

The vehicle suspension system of front and rear wheels were semi-elliptical leaf springs. Each suspension was equipped with four plates and a damper. A $10 \mathrm{~mm}$ thickness of steel plate was on the top, and the other three were $8 \mathrm{~mm}$ thick plates. The length of front suspension plates was $1247 \mathrm{~mm}$, and the center of plates was connected to the fixed contact of the front axle. The length of rear suspension plates was $1366 \mathrm{~mm}$, and the center fixed contact was connected to the differential. The gap between each piece was $5 \mathrm{~mm}$. Four damper tubes were installed in the vertical direction. The stability bar was attached to the bottom two front damper tubes, as shown in Figure 8. 


\subsection{Driveline system}

The driveline system included a $75 \mathrm{~kW}$ permanent magnet synchronous motor, clutch, six-speed manual gearbox, drive shaft, and differential [5], as shown in Figure 9.

Table 1. Flexible body modes.

\begin{tabular}{|c|c|c|}
\hline \multicolumn{3}{|c|}{ Flexible body modal frequency } \\
\hline Order & Mode Frequency(hz) & Mode Type \\
\hline 7 & 18.258284 & Longitudinal torsion(back fixed) \\
\hline 8 & 22.830112 & Vertical bending(back fixed) \\
\hline 9 & 23.845562 & $1^{\text {st }}$ lateral bending \\
\hline 10 & 27.841775 & $1^{\text {st }}$ longitudinal torsion \\
\hline 11 & 30.379962 & Lateral bending and longitudinal torsion \\
\hline 12 & 30.925637 & $\begin{array}{l}\text { Lateral bending and longitudinal torsion } \\
\qquad \text { ( } 2 \text { fixed) }\end{array}$ \\
\hline 13 & 31.372244 & $\begin{array}{l}\text { Lateral bending and longitudinal torsion } \\
\text { (middle fixed) }\end{array}$ \\
\hline 14 & 33.339106 & Lateral bending(back fixed) \\
\hline 15 & 33.643737 & Longitudinal bending(back fixed) \\
\hline 16 & 35.645866 & $\begin{array}{l}\text { Longitudinal bending and vertical } \\
\text { bending(back fixed) }\end{array}$ \\
\hline 17 & 35.865369 & $1^{\text {st }}$ Vertical bending \\
\hline 18 & 37.269394 & Vertical bending and lateral bending \\
\hline 19 & 37.590479 & $2^{\text {nd }}$ lateral bending \\
\hline 20 & 39.564707 & Lateral bending ( 2 fixed $)$ \\
\hline 21 & 40.209258 & $3^{\text {rd }}$ lateral bending \\
\hline 22 & 41.208339 & Vertical and torsion(front right wheel) \\
\hline 23 & 41.733302 & Vertical bending(front end) \\
\hline 24 & 42.706628 & $2^{\text {nd }}$ longitudinal torsion \\
\hline 25 & 43.900234 & Longitudinal torsion (steering system) \\
\hline
\end{tabular}




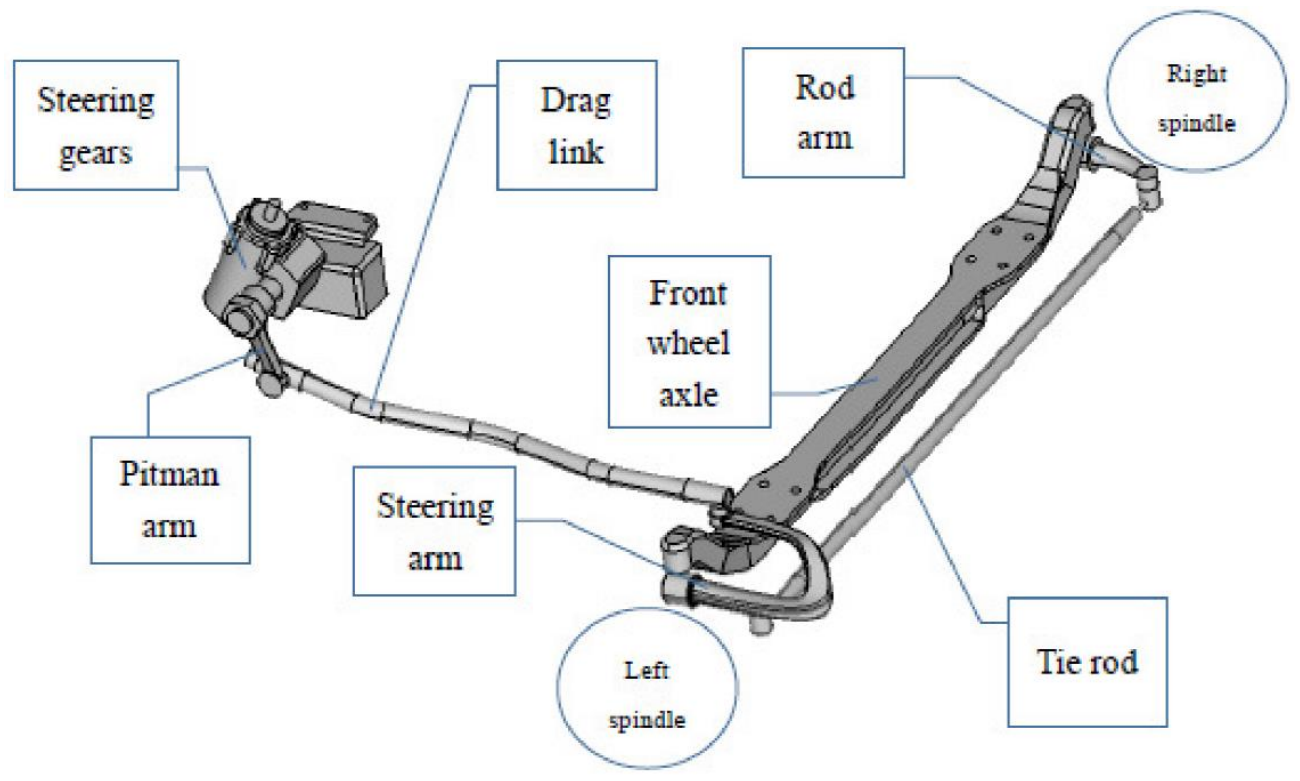

Figure 7. Steering system configuration diagram.

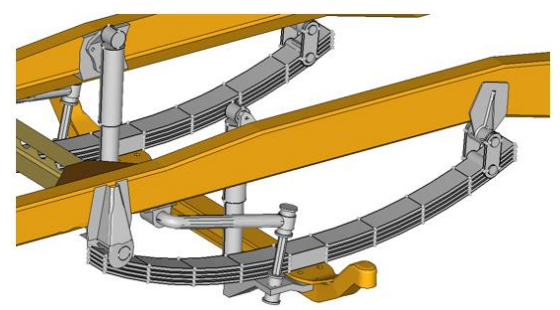

Figure 8. Suspension system configuration diagram.

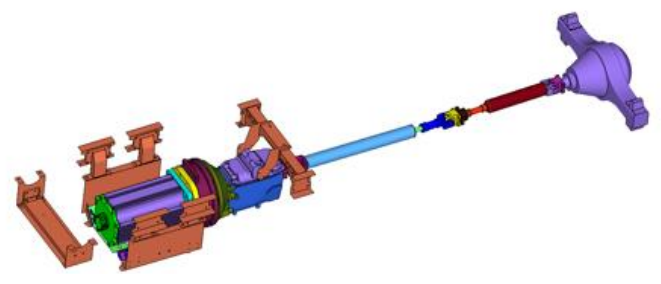

Figure 9. Suspension system configuration diagram.

\section{Simulation and analysis}

\subsection{Simulation conditions}

This research referenced the ISO7401 regulation of the road vehicles transient open-loop response test method which was suitable for passenger cars and light trucks. The vehicle speed must reach 100 kilometers per hour, and the speed difference should not exceed 2 kilometers per hour. The yaw rate should be in steady state with the difference less than 0.5 degrees per second. The steering signal should increase from $10 \%$ to $90 \%$ within 0.15 seconds, and the throttle position should not change during the steering test. Tests were divided into the left turn and right turn, and the steering wheel angle was determined by the steady-state tests of constant radius circle [5]. 
The total simulation time was 40 seconds, and steering wheel angle rotated to 25.91 degrees from 10 and to 10.15 seconds, as shown in Figure 10. The left lateral acceleration would reach 400 meters per second after turning the steering. Simulation parameters are shown in Table 2.

Table 2. Steering turn parameters.

\begin{tabular}{|c|c|}
\hline Parameters of Simulation & Value \\
\hline Velocity $v_{x}$ & $100 \mathrm{~km} / \mathrm{hr}$ \\
\hline Steady state lateral acceleration $a_{Y}$ & $4 \mathrm{~m} / \mathrm{s}^{2}$ \\
\hline Correction steering wheel angle $\delta_{\text {cor }}$ & $0.42^{\circ}$ \\
\hline Steady state steering wheel angle $\delta_{h @ s s}$ & $25.919^{\circ}(L), 27.023^{\circ}(R)$ \\
\hline
\end{tabular}

\section{Vehicle velocity}

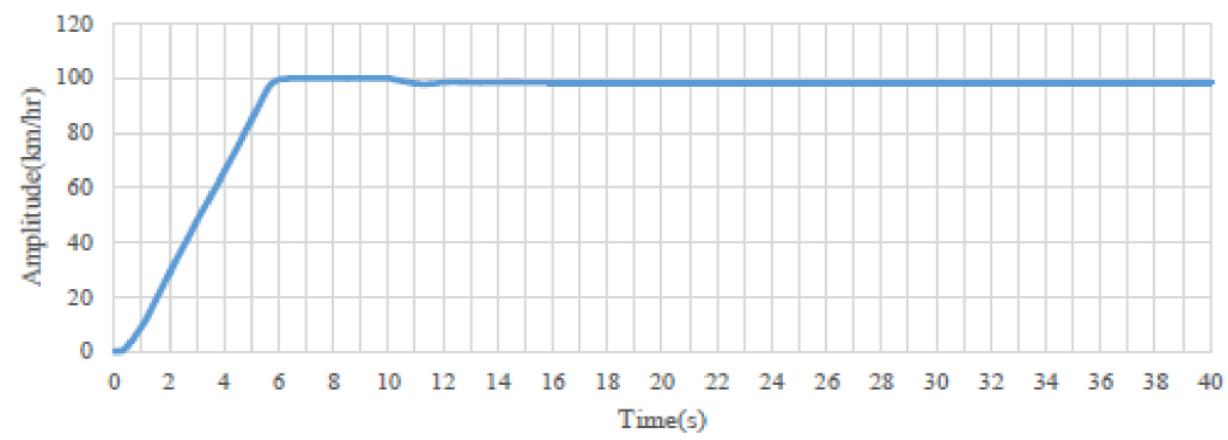

Bus simulation speed

Steering angle

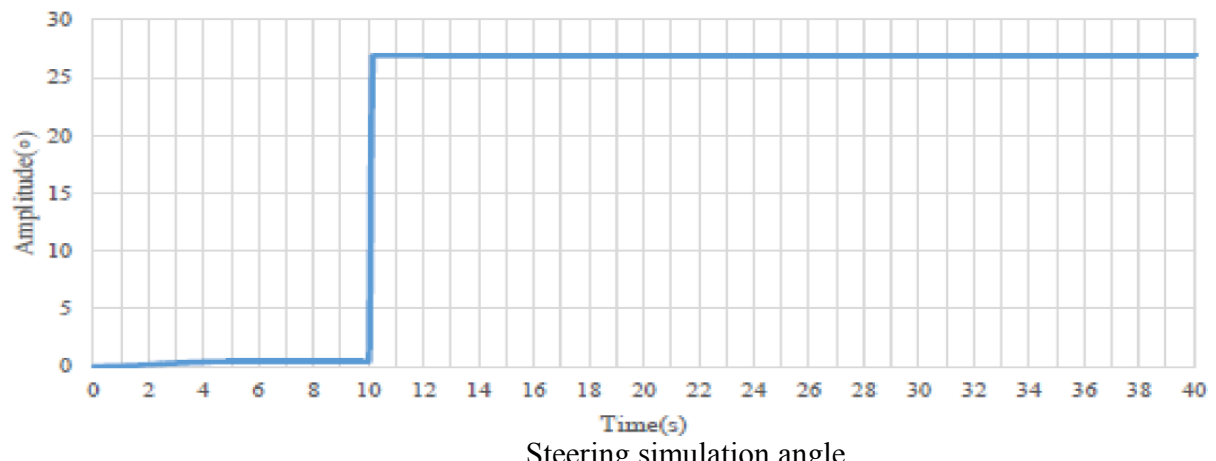

Figure 10. Vehicle speed and steering angle.

\subsection{Simulation results and analysis}

In this research, the steering step input simulations were analyzed. In addition to the comparison between left and right turns, the comparison between the rigid body and flexible body simulations was also included.

During the right turn, the lateral acceleration of rigid and flexible body simulation was shown in Figure 11. The flexible body simulation data reached the steady state later than the rigid body simulation, which represented the flexible body had a longer response time. The deformation of 
vehicle body structure caused vibration during the steering turn, so the time to reach the steady-state was delayed. Yaw rate response was shown in Figure 12. The flexible body simulation also showed a longer response time. Over time response of roll angle was shown in Figure 13. Since the flexible of bus structure, the flexible body simulation had longer response time and higher peak value.

Lateral acceleration (right turn)

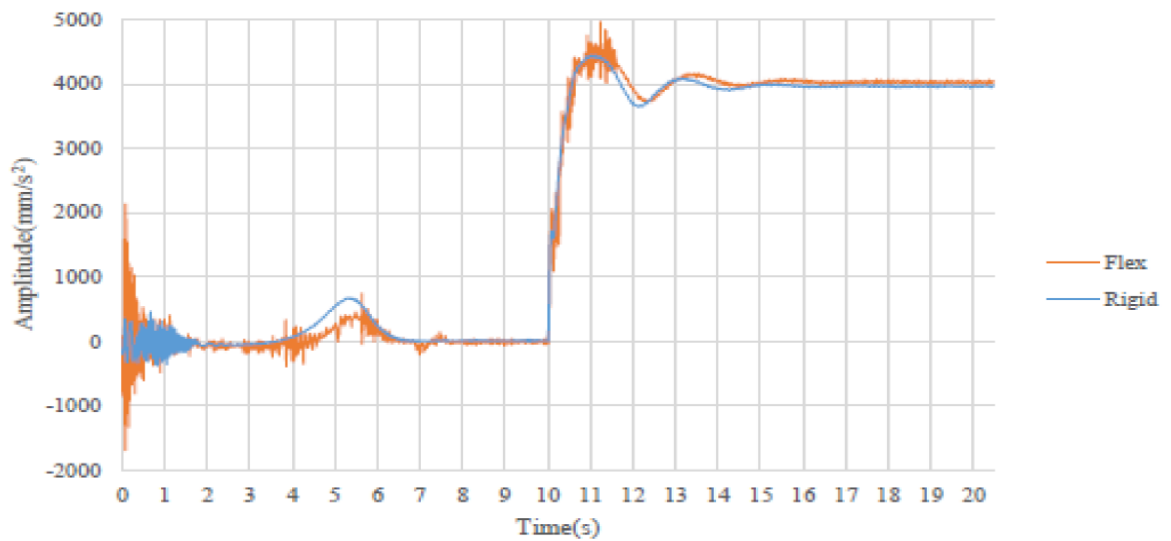

Figure 11. Lateral acceleration during right turn.

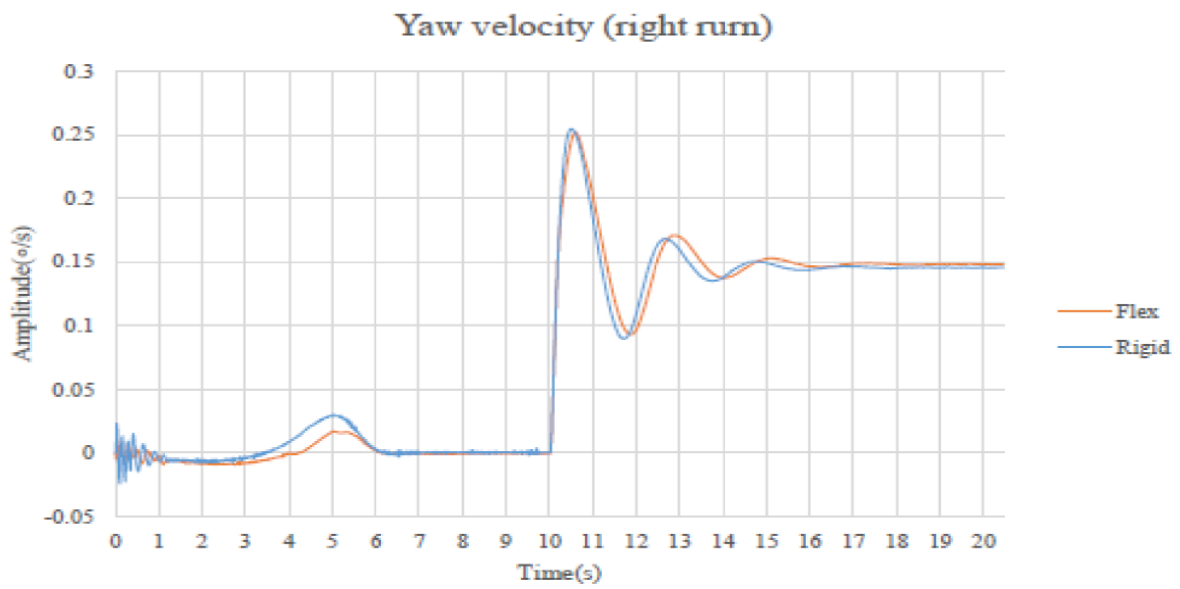

Figure 12. Yaw velocity during right turn.

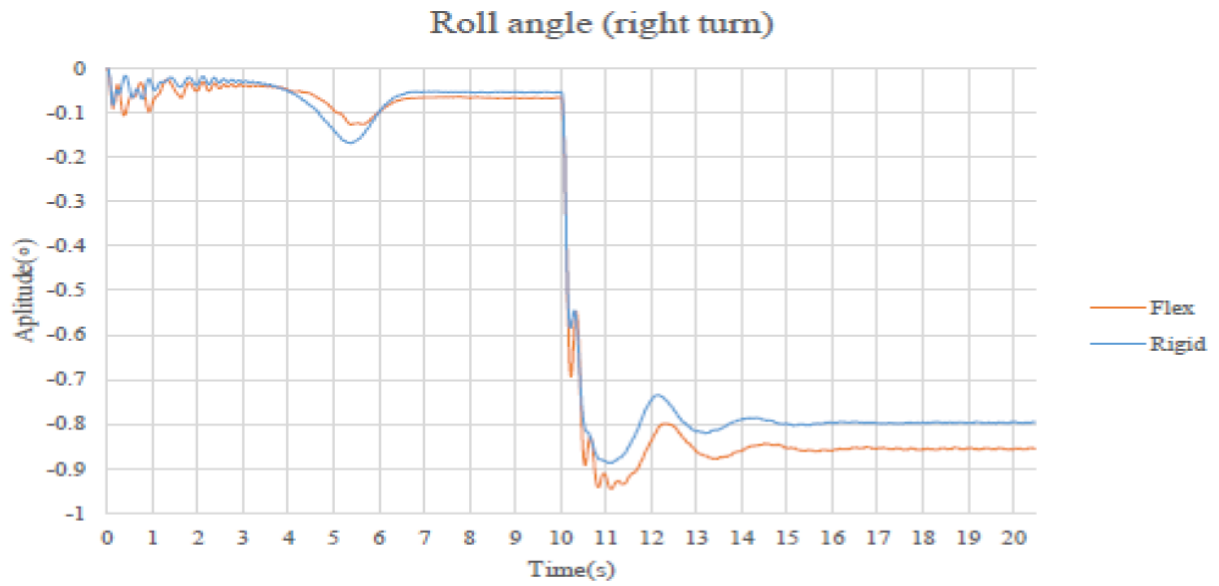

Figure 13. Roll angle during right turn. 
For left turn simulation, the lateral acceleration, yaw velocity and roll angle response were presented in Figures 14, 15 and 16, respectively. Since the flexible body dynamic simulation allowed deformations of vehicle body, the response time to reach steady-state of flexible body simulation was longer than that of the rigid body dynamic simulation. The peak values of flexible body simulation were also higher than that of the rigid body simulation.

Lateral acceleration (left)

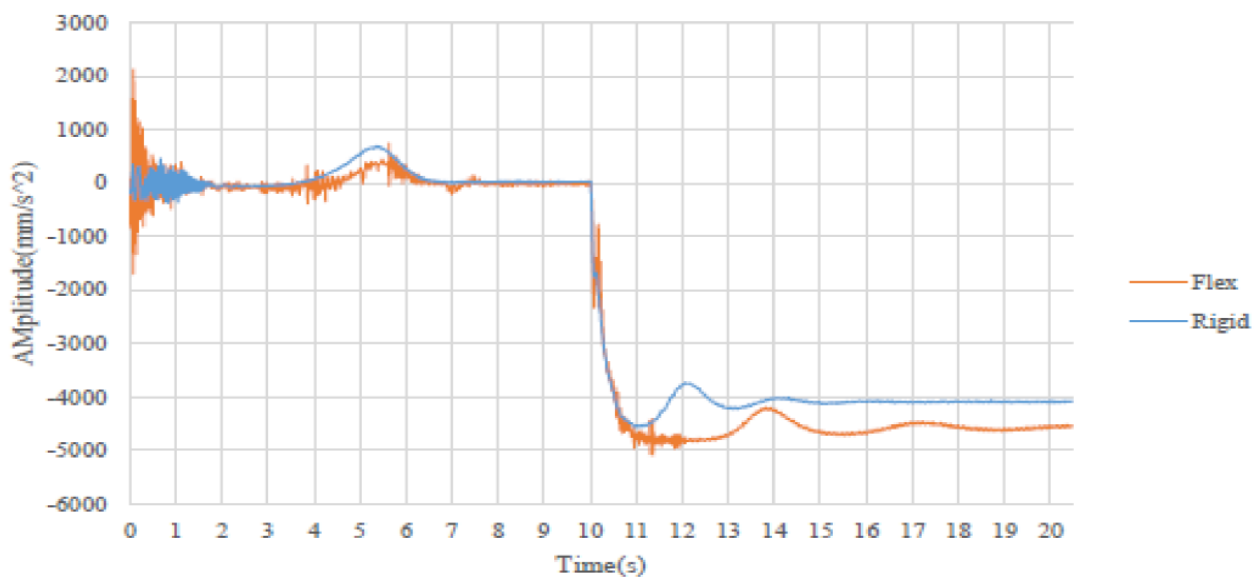

Figure 14. Lateral acceleration during left turn.

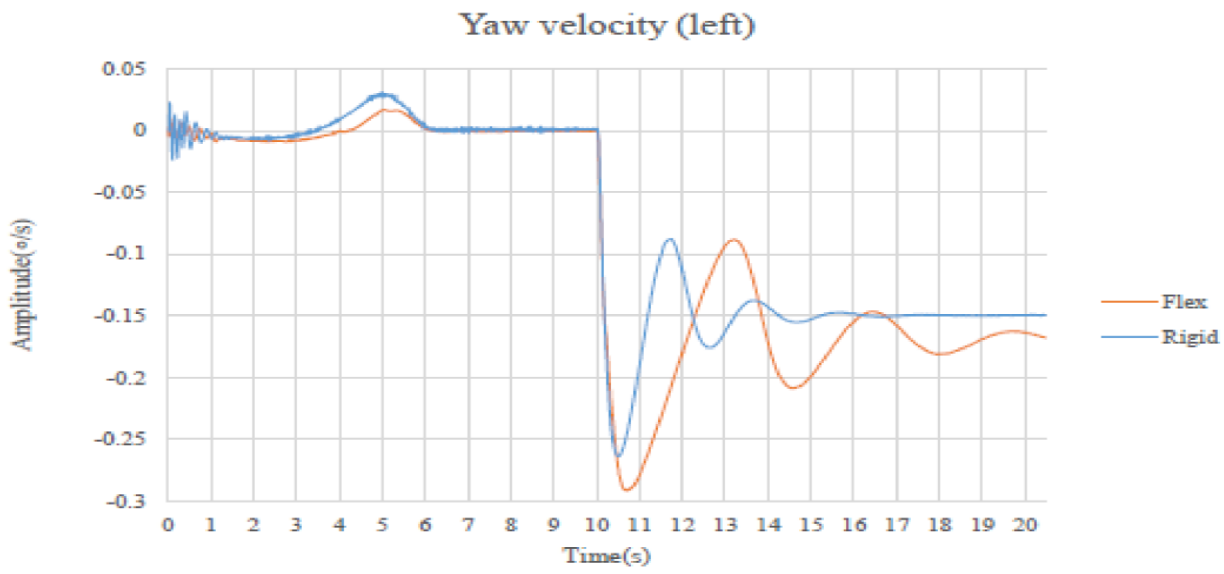

Figure 15. Yaw velocity during left turn.

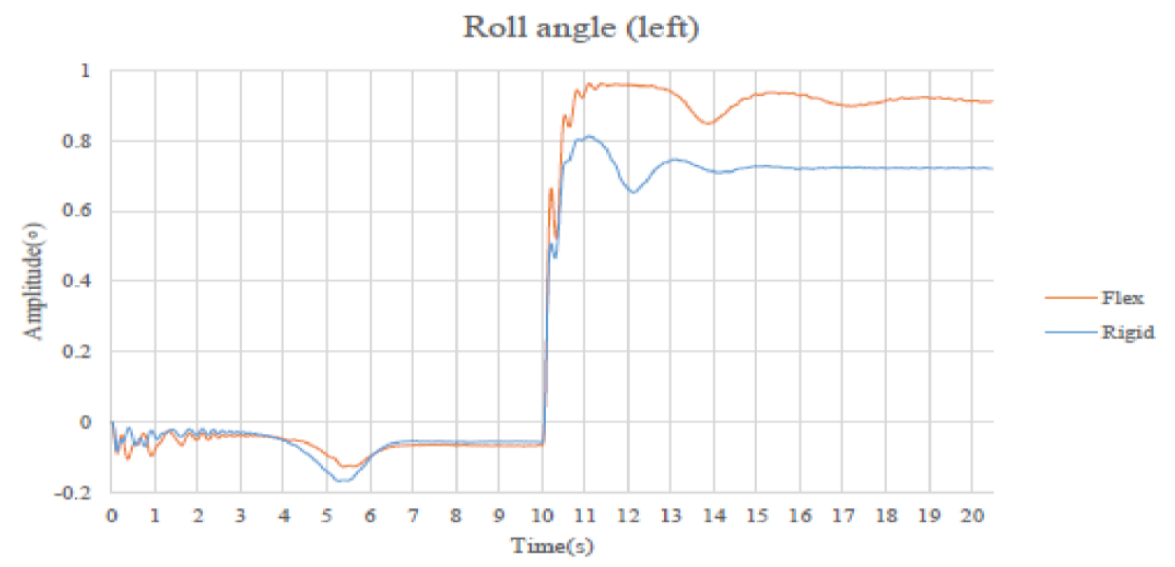

Figure 16. Roll angle during left turn. 
The response time of flexible body simulation was longer, because the bus body was deformable which extended the vibration time. With the batteries and seats, the vehicle center of gravity shifted to the left, which caused the higher values of lateral acceleration, yaw velocity and roll angle during the left turn simulation. Table 3 presented the summary difference table of step steering input response between the flexible body and rigid body simulations.

Table 3. Summary table of step steering input response.

\begin{tabular}{|l|c|}
\hline \multicolumn{2}{|c|}{ Percentage of data difference of Flexible body from rigid body } \\
\hline Parameter & Percentage of data difference \\
\hline Steady-state yaw velocity response gain & $+7.14 \%$ \\
\hline Lateral acceleration response time & $+32.34 \%$ \\
\hline Yaw velocity response time & $+8.47 \%$ \\
\hline Roll angle response time & $+5.51 \%$ \\
\hline Lateral acceleration peak response time & $+15.51 \%$ \\
\hline Yaw velocity peak response time & $+33.06 \%$ \\
\hline Roll angle peak response time & $+13.43 \%$ \\
\hline Overshoot value of lateral acceleration & $-12.13 \%$ \\
\hline Overshoot value of yaw velocity & $-6.02 \%$ \\
\hline Overshoot value of roll angle & $-35.32 \%$ \\
\hline
\end{tabular}

\section{Conclusions}

This research presented dynamics simulations of electric bus, and replaced the rigid bodies with flexible bodies in multi-body dynamic model. According to the steering test regulations, dynamics simulations were performed and the results were presented. The conclusions were presented as below.

1. The elastic deformation of the body caused the vehicle vibration response times lengthen. Comparing with the rigid body model which did not have body flexibility, the flexible body model which represented the elastic deformation during steering turning simulation was closer to the actual performance of real vehicle.

2. The flexible vehicle parts could exhibit more detail motion and vibration, and this vibration would pass through vehicle structure.

3. The geometry of vehicle was not symmetric, which caused the higher normal load of right rear tire during the left turn simulation. This higher tire load would act on the vehicle body and caused higher body deformation. This was the reason that left turn had higher yaw velocity and roll angle. This behavior would not be predicted with the rigid body model. So, the flexible body simulation could provide more realistic data.

4. From the tire load data, the vehicle body's longitudinal torque was different between the left turn and the right turn. This would affect the steering performance. With the longer vehicle body, such as bus and truck, the flexible body model provided more accurate results of the simulation.

\section{References}

1. J.M.P. Dias and M.S. Pereira, Multibody System Dynamics, 1(3), 303-322 (1997)

2. J.S. Chen and H.Y. Hwang, Advances in Mechanical Engineering, 5 (2013) 
3. J.S. Chen, Advances in Mechanical Engineering, 7(3) (2015)

4. J.A.C. Ambrósio and J.P.C. Gonçalves, Multibody System Dynamics, 6(2), 163-182 (2001)

5. ISO 7401 2011, Road vehicles - Lateral transient response test methods - Open-loop test methods

6. Z. Lozia and W. Pieniazek, SAE Technical Paper, No. 2002-01-1184 (2002)

7. S. Chen, D. Wang, A. Zuo, Z. Chen, Y. Sun and J. Zan, Study on handling and stability of a passenger car based on rigid-flexible coupling model, 2010 International Conference on Computer, Mechatronics, Control and Electronic Engineering, Changchun, China, 615-620 (2010)

8. B. Göttlicher and K. Schweizerhof, Computers \& Structures, 83(25-26), 2035-2051 (2005)

9. S. Azadi, M. Vaziri and M. Hoseini, Vehicle System Dynamics, 48(5), 587-617 (2010) 